polyclonal antisera ${ }^{29}$, followed by horseradish peroxidase-conjugated protein A. Lysates were immunoprecipitated with either $5 \mu \mathrm{g}$ anti-HA 12CA5 or $3 \mu \mathrm{g}$ anti-Myc 9E10 monoclonal antibody for $2 \mathrm{~h}$ at $4{ }^{\circ} \mathrm{C}$, followed by incubation with protein $\mathrm{G}-\mathrm{Sepharose}$ for $1 \mathrm{~h}$ at $4{ }^{\circ} \mathrm{C}$. For pulse-chase analysis, cells were labelled for $30 \mathrm{~min}$ with ${ }^{35} \mathrm{~S}$-methionine/cysteine, chased in medium with excess unlabelled methionine/cysteine for varying times and collected by detergent lysis. After immunoprecipitation and SDS-PAGE, gels were visualized by fluorography and quantified by densitometry (Molecular Analysis, Biorad). For subcellular fractionation, adherent cells were detached by incubation with EDTA and gently disrupted by Dounce homogenization. Cellular lysates were layered on $45 \%$ sucrose cushions and membrane and cytosolic/ microsomal fractions recovered after centrifugation at 7,000 $\mathrm{g}$ for $20 \mathrm{~min}$.

Received 16 January; accepted 12 May 1997.

1. Blumenthal, E. M. \& Kaczmarek, L. K. The minK potassium channel exists in functional and nonfunctional forms when expressed in the plasma membrane of Xenopus oocytes. J. Neurosci. 14, 3097-3105 (1994)

2. Wang, K.-W. \& Goldstein, S. A. N. Subunit composition of $\operatorname{minK}$ potassium channels. Neuron 14 1303-1309 (1995).

Tai, K. K., Wang, K. W. \& Goldstein, S. A. N. MinK potassium channels are heteromultimeric complexes. J. Biol. Chem. 272, 1654-1658 (1997).

4. Takumi, T. et al. Alteration of channel activities and gating by mutations of slow $I_{\mathrm{sK}}$ potassium channel. J. Biol. Chem. 2266, 22192-22198 (1991).

. Blumenthal, E. M. \& Kaczmarek, L. Modulation by cAMP of a slowly activating potassium channel expressed in Xenopus oocytes. J. Neurosci. 12, 290-295 (1992).

6. Busch, A. E., Kavanaugh, M. P., Varnum, J. P. \& Adelman, J. P. Regulation by second messengers of the slowly activating, voltage-dependent potassium current expressed in Xenopus oocytes. J. Physiol. 450 491-502 (1992).

7. Goldstein, S. A. N. \& Miller, C. Site-specific mutations in a minimal voltage-dependent K+ channel alter ion selectivity and open-channel block. Neuron 7, 403-408 (1991).

8. Wang, K. W., Tai, K. K. \& Goldstein, S. A. N. MinK residues line a potassium channel pore. Neuron 16, 571-577 (1996).

9. Sanguinetti, M. C. et al. Coassembly of $\mathrm{K}_{\mathrm{V}} \mathrm{LQTl}$ and $\operatorname{minK}$ (IsK) proteins to form cardiac $\mathrm{I}_{\mathrm{Ks}}$ potassium channel. Nature 384, 80-83 (1996).

10. Barhanin, J. et al. $\mathrm{K}_{\mathrm{V}} \mathrm{LQT1}$ and IsK ( $\mathrm{minK}$ ) proteins associate to form $\mathrm{I}_{\mathrm{Ks}}$ cardiac potassium current. Nature 384, 80-83 (1996)

11. Sanguinetti, M. C., Jiang, C., Curran, M. E. \& Keating, M. T. A mechanistic link between an inherited and an acquired cardiac arrhythmia: HERG encodes the $\mathrm{I}_{\mathrm{Kr}}$ potassium channel. Cell 81, 299-307 (1995).

12. Trudeau, M. C., Warmke, J. W., Ganetzky, B. \& Robertson, G. A. HERG, a human inward rectifier in the voltage-gated potassium channel family. Science 269, 92-95 (1995).

13. Sanguinetti, M. C. \& Jurkiewicz, N. K. Two components of the delayed rectifier $\mathrm{K}^{+}$current: differential sensitivity to block by class III antiarrhythmic agents. J. Gen. Physiol. 96, 195-215 (1990).

14. Sanguinetti, M. C. \& Jurkiewicz, N. K. Delayed rectifier outward $\mathrm{K}^{+}$current is composed of two currents in guinea pig atria cells. Am. J. Physiol. 260, H393-H399 (1991).

15. Yang, T., Kupershmidt, S. \& Roden, D. M. Anti-minK antisense decreases the amplitude of the rapidly activating cardiac delayed rectifier $\mathrm{K}^{+}$current. Circ. Res. 77, 1246-1253 (1995).

16. Lesage, F. et al. Are Xenopus oocytes unique in displaying functional IsK channel heterologous expression? Receptors and Channels 1, 143-152 (1993).

17. Margiotta, J. F., Berg, D. K. \& Dionne, V. E. Cyclic AMP regulates the proportion of functiona acetylcholine receptors on chicken cilliary ganglion neurons. Proc. Natl Acad. Sci. USA 84, 8155-8159 (1987).

18. Pardo, L. A. et al. Extracellular K+ specifically modulates a brain K+ channel. Proc. Natl Acad. Sci. USA 89, 2466-2470 (1992).

19. Brahmajothi, M. V. et al. In situ hybridization reveals extensive diversity of $\mathrm{K}+$ channel mRNA in isolated ferret cardiac myocytes. Circ. Res. 78, 1083-1089 (1996).

20. Choy, A.-M. J., Kupershmidt, S., Lang, C. C., Pierson, R. N. \& Roden, D. M. Regional expression of HERG and KVLQT1 in heart failure. Circulation 94, 1-I164 (1996).

21. Curran, M. E. et al. A molecular basis for cardiac arrhythmia: HERG mutations cause long QT syndrome. Cell 80, 795-803 (1995).

22. Wang, Q. et al. Positional cloning of a novel potassium channel gene: KVLQT1 mutations cause cardiac arrhythmias. Nature Genet. 12, 17-25 (1996).

23. Roden, D. M. et al. Multiple mechanisms in the long-QT syndrome: Current knowledge, gaps, and future directions. Circ. Res. 94, 1996-2012 (1996).

24. Vetter, D. E. et al. Inner ear defects induced by null mutation of the isk gene. Neuron 17, 1251-1264 (1996).

25. Sugimoto, T. et al. Immunohistochemical study of a rat membrane protein which induces a selective potassium permeation: its localization in the apical membrane portion of epithelial cells. J. Membr. Biol. 113, 39-47 (1990).

26. Sakagami, M. et al. Cellular localization of rat Isk protein in the stria vascularis by immunohistochemical observation. Hearing Res. 56, 168-172 (1991).

27. Freeman, L. C. \& Kass, R. S. Expression of a minimal $\mathrm{K}^{+}$channel protein in mammalian cells and immunolocalization in guinea pig heart. Circ. Res. 73, 968-973 (1993).

28. Attali, B. et al. Cloning, functional expression, and regulation of two $\mathrm{K}^{+}$channels in human $\mathrm{T}$ lymphocytes. J. Biol. Chem. 267, 8650-8657 (1992).

29. Pond, A. L., Petrecca, K., Van Wagoner, D. R., Shrier, A. \& Nerbonne, J. M. Distinct isoforms of ERG expressed in rat and human heart. Circ. Res. (submitted).

30. Smith, P. L., Baukrowitz, T. \& Yellen, G. The inward rectification mechanism of the HERG cardiac potassium channel. Nature 379, 833-836 (1996).

Acknowledgements. We thank G. Robertson for HERG cDNA, J. Nerbonne and A. Pond for HERG antisera, K. Sawada for E4031, and V. S. Srinivas for technical assistance. This work was supported by funds from the AECOM Molecular Cardiology Endowment to T.V.M., M.B.M. and G.I.F., and by grants to G.I.F. from the American Heart Association (Established Investigator) and the Council for Tobacco Research and to S.A.N.G. from the NIH-NIGMS and Donaghue Foundation.

Correspondence and requests for materials should be addressed to T.V.McD. (e-mail: mcdonald@ aecom.yu.edu).

\section{P. falciparum rosetting mediated by a parasite-variant erythrocyte membrane protein and complement-receptor 1}

\section{J. Alexandra Rowe ${ }^{\dagger}+$ Joann M. Moulds $\ddagger$, Christopher I. Newbold $\dagger$ \& Louis H. Miller}

* Laboratory of Parasitic Diseases, NIAID, NIH, 9000 Rockville Pike, Bethesda, Maryland, 20892, USA

$\dagger$ Molecular Parasitology Group, Institute of Molecular Medicine,

John Radcliffe Hospital, Oxford OX3 9DU, UK

$\$$ Division of Rheumatology and Clinical Immunogenetics,

University of Texas-Houston Medical School, Houston, Texas, 77030, USA

The factors determining disease severity in malaria are complex and include host polymorphisms, acquired immunity and parasite virulence ${ }^{1}$. Studies in Africa have shown that severe malaria is associated with the ability of erythrocytes infected with the parasite Plasmodium falciparum to bind uninfected erythrocytes and form rosettes ${ }^{2-5}$. The molecular basis of rosetting is not well understood, although a group of low-molecular-mass proteins called rosettins have been described as potential parasite ligands ${ }^{6}$. Infected erythrocytes also bind to endothelial cells, and this interaction is mediated by the parasite-derived variant erythrocyte membrane protein PfEMP1 (refs 7, 8), which is encoded by the var gene family ${ }^{9-11}$. Here we report that the parasite ligand for rosetting in a $P$. falciparum clone is PfEMP1, encoded by a specific var gene. We also report that complement-receptor 1 (CR1) on erythrocytes plays a role in the formation of rosettes and that erythrocytes with a common African CR1 polymorphism $\left(\mathrm{Sl}\left(\mathrm{a}^{-}\right)\right)^{12}$ have reduced adhesion to the domain of PfEMP1 that binds normal erythrocytes. Thus we describe a new adhesive function for PfEMP1 and raise the possibility that CR1 polymorphisms in Africans that influence the interaction between erythrocytes and PfEMP1 may protect against severe malaria.

We studied the role of PfEMP1 in rosetting using the clone R29 of P. falciparum, which was divided into isogeneic rosetting $\left(\mathrm{R}_{2} 9 \mathrm{R}^{+}\right)$ and non-rosetting (R29R $\mathrm{R}^{-}$) subpopulations by sedimentation in gelatin $^{13}$ (see Methods). Each parasite genome is estimated to contain 50-150 var genes ${ }^{11}$, and switching of expression from one $v a r$ to another gives rise to antigenic variation ${ }^{14}$. To study the var genes expressed by R29R ${ }^{+}$and $\mathrm{R}_{2} 9 \mathrm{R}^{-}$, we used the polymerase chain reaction with reverse transcription (RT-PCR) and degenerate oligonucleotide primers to the first cysteine-rich Duffy-binding-like domain (DBL-1) of the var genes. This DBL-1 domain of known var genes has regions of very high sequence homology interspersed with regions of variable sequence ${ }^{11}$. The RT-PCR product from R29R ${ }^{+}$ RNA consisted of a single major band, whereas three distinct bands were visible from R29R ${ }^{-}$RNA (Fig. 1a). RT-PCR products were cloned into a pCRII vector and those with inserts of the appropriate size for DBL-1 (400-600 base pairs (bp)) were sequenced. From the cloning of the $\mathrm{R}_{2} 9 \mathrm{R}^{+} \mathrm{RT}-\mathrm{PCR}$ product, 13 recombinant plasmids contained inserts of $400-600$ base pairs. These all contained the DBL-1 sequence (called $R 29 R^{+}$var1; Fig. $1 \mathrm{~b}$ ), which is identical to the var sequence described for the R29 clone ${ }^{10}$. From the cloning of the R29R ${ }^{-}$RT-PCR product, five different DBL-1 sequences were detected, namely $R 29 R^{-}$var2 to $R 29 R^{-}$var6 (Fig. $1 \mathrm{~b}$ ). None of the recombinant plasmids from the $\mathrm{R}_{2} 9 \mathrm{R}^{-} \mathrm{RT}-\mathrm{PCR}$ product contained the $R 29 R^{+}$var sequence found in rosetting parasites. Using primers specific for $R 29 R^{+}$varl, we confirmed by RT-PCR that this gene is specific to the $R 29 \mathrm{R}^{+}$population and is not expressed by the $R 29 \mathrm{R}^{-}$ 
non-rosetting parasites (Fig. 1c). The presence of amplifiable RNA in the R29R $\mathrm{R}^{-}$sample was demonstrated by RT-PCR with specific primers to $R 29 R^{-}$var3 which gave a 550 -bp band with $\mathrm{R}^{2} 9 \mathrm{R}^{-} \mathrm{RNA}$ (Fig. 1c). Thus, a particular var gene, $R 29 R^{+}$varl, is expressed by rosetting parasites but not by non-rosetting parasites of the R29 clone. This finding is consistent with a role for var/PfEMP1 in rosetting.

To examine the functional properties of $R 29 R^{+} v a r 1$, the sequence was extended by PCR-walking using vectorette libraries ${ }^{15}$. We obtained seven overlapping clones encoding all of exon 1 (the entire extracellular domain and the transmembrane region), the intron, and the $5^{\prime}$ half of exon 2 (the acidic intracellular domain). The clones were sequenced in both directions and gave an open reading frame of 8.2 kilobases $(\mathrm{kb}) . R 29 R^{+}$var 1 has the characteristic var gene structure ${ }^{9,11}$, with the extracellular portion consisting of four DBL domains and a cysteine-rich interdomain region (CIDR) (Fig. 1d).

To study the binding properties of $R 29 R^{+}$var1 to red blood cells (RBCs), constructs were made to express individual DBL domains and the CIDR in COS-7 cells as chimaeric proteins with the herpes simplex virus glycoprotein $\mathrm{D}^{16}$. COS-7 cells were transiently transfected, and surface expression of DBL domains was determined by immunofluorescence assay with monoclonal antibodies against the herpes simplex glycoprotein $\mathrm{D}^{17}$. Each domain of the $R 29 R^{+}$var1 gene was expressed on the surface of COS-7 cells except DBL-4 (Fig. 1d). The transfected COS-7 cells were tested for their ability to bind RBC. DBL- 1 of $R 29 R^{+}$varl bound RBC, whereas DBL-2, DBL-3, and CIDR did not (Fig. 1d, e). As evidence that not all DBL-1 domains bind RBC, DBL-1 expressed by a non-rosetting parasite (A4 (ref. 10); gift from J. Smith) was expressed on $\sim 2 \%$ of COS-7 cells but did not bind RBC.

We studied the effect of the anti-CD36 monoclonal antibody OKM5 on RBC binding to DBL- 1 of $R 29 R^{+}$varl because PfEMP1 is known to bind to CD36 (refs 7, 8) and previous work has shown that CD36 is expressed at low levels on RBC and can rarely act as a rosetting receptor ${ }^{18}$. OKM5 $\left(100 \mu \mathrm{g} \mathrm{ml}^{-1}\right)$ did not inhibit RBC binding to DBL-1 of $R 29 R^{+}$var1 expressed in COS-7 cells (36 positive cells with OKM5, compared with 32 positive cells with an isotype-matched control; mean binding in 50 fields at $200 \times$ magnification from two experiments). R29 rosetting also is not inhibited by OKM5 (ref. 19), so CD36 binding does not play a role in the interaction between PfEMP1 and RBC described here.

Confirmation that binding of RBC to DBL-1 is the basis of a

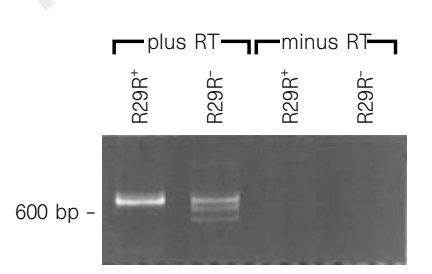

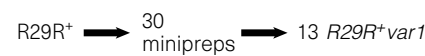

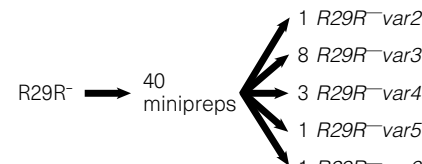

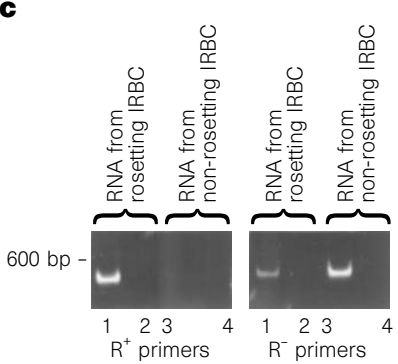

Table 1 Binding of CR1-deficient RBC to DBL-1 of $R 29 R^{+}$var1 expressed in cos-7 cells

Donor

RBC binding*

CR1-deficient (frozen)

Control

CR1-deficient (M.H.)

Control

CR1-deficient (B.S.)

Control

0

27

0

45

22

* Number of positive COS-7 cells in 50 fields at $200 \times$ magnification. Data shown represent the mean binding from two independent experiments for each sample.

rosetting was hampered by the fact that the $\mathrm{RBC}$ receptor for $\mathrm{R} 29$ was unknown. We therefore tested $23 \mathrm{RBC}$ variants that were negative or null for a range of high-frequency blood group antigens to determine whether any of these RBC were unable to form rosettes with five $P$. falciparum clones/lines. Initial experiments were with frozen $\mathrm{RBC}$, and the experiments were repeated with fresh RBC for any variant that showed reduced rosetting. The Knops null RBC was the only one to show consistently reduced rosetting (Fig. 2a). Knops null RBC express low copy numbers of complement-receptor 1 , having fewer than $100 \mathrm{CR} 1$ molecules per RBC compared with the normal range of 100 to 800 (refs 20,21). Previous work had shown that the $\mathrm{ABO}$ blood grouping influences the size of rosettes formed but not the overall rosette frequency ${ }^{22}$. Our results, however, were not dependent on the ABO blood group of the RBC. To exclude any artefact resulting from the purification of infected $\mathrm{RBC}$ for the rosette-reformation assay, fresh CR1-deficient RBC were obtained from another donor (B.S.; CR1 copy number 60), and the rosetting $\mathrm{R}_{2} 9 \mathrm{R}^{+}$parasites were cultured in vitro for 9 days in the CR1deficient and control normal RBC. Blinded assessments of rosette frequency were made every cycle, and the reduced rosetting of CR1deficient RBC was confirmed (Fig. 2b). The parasitaemia in CR1deficient RBC was equivalent to the control, and Giemsa-stained smears showed that the parasites were morphologically normal. We have therefore demonstrated reduced rosetting of CR1-deficient $\mathrm{RBC}$ from four different donors (two frozen and two fresh) either by rosette reformation assay or by continuous culture.

Our results suggest that CR1 plays a role in the formation of rosettes. We therefore examined the effect of soluble recombinant CR1 (sCR1; ref. 23) on rosetting. sCR1 inhibited rosette formation in three out of four parasite clones/lines tested (Fig. 2c, d). These reverse transcriptase (RT) were per-

\section{d}

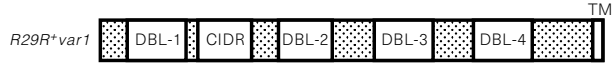

Construct

$\mathrm{R}^{2} 9 \mathrm{R}^{+} \mathrm{db} 11$ R29R+cidr $R 29 R^{+} d b / 2$ $R 29 R^{+} d b / 3$ $R 29 R^{+} d b / 4$

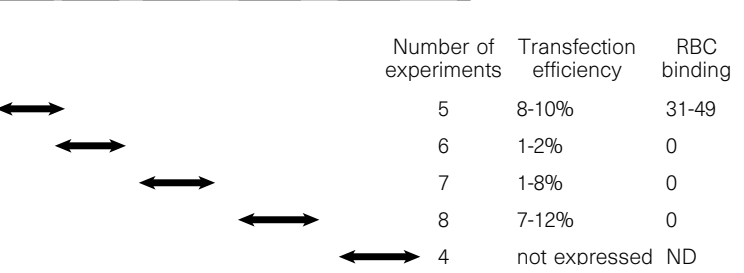

e

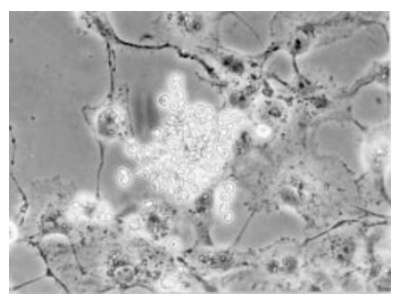

Figure 1 Var gene expression and RBC binding in P. falciparum clone R29. a, RT$\mathrm{PCR}$ analysis of var gene expression in rosetting $\left(\mathrm{R}^{2} 2 \mathrm{R}^{+}\right)$and non-rosetting $\left(\mathrm{R}_{2} 9 \mathrm{R}^{-}\right.$ ). To control for possible genomic DNA contamination, reactions with and without formed in parallel. b, Cloning and sequence of RT-PCR products from a. All minipreps with inserts of 400-600 bp were sequenced. c, RT-PCR analysis with specific primers to $R 29 R^{+}$var1 ( $\mathrm{R}^{+}$primers) and $R 29 R^{-}$var3 ( $\mathrm{R}^{-}$primers). IRBC, infected RBC. d, Expression constructs and RBC binding of domains of $R 29 R^{+}$var1. ND, not determined. e, RBC binding to COS-7 cell transiently transfected with DBL-1 of R29R'var1. 
results are consistent with the importance of CR1 in the formation of rosettes. The reason for the failure of sCR1 to inhibit rosetting by $\mathrm{PAR}^{+}$is unknown, although it may relate to additional receptors or affinity of PAR ${ }^{+}$for sCR1.

CR1-deficient RBC were used to determine the specificity of RBC binding to DBL-1 of $R 29 R^{+}$var1. CR1-deficient RBC from three donors showed reduced or absent binding to DBL-1 compared with control RBC (Table 1$)$. Thus, a particular var gene $\left(R 29 R^{+}\right.$var 1$)$ is expressed by rosetting but not by non-rosetting parasites of the R29 clone, and DBL-1 of this var gene binds RBC with the same specificity as R29 rosetting parasites. Together, these data provide strong evidence that PfEMP1 encoded by $R 29 R^{+}$varl is the rosettemediating ligand in R29.

The high mortality of $P$. falciparum in endemic areas has resulted in the selection for polymorphisms that afford protection from severe malaria ${ }^{24,25}$. The association between the rosetting phenotype and severe disease from $P$. falciparum suggests that natural RBC variants that support rosetting less well may have been selected to a high frequency by reducing mortality from malaria. The Sl( $\left.\mathrm{a}^{-}\right) \mathrm{CR} 1$ blood-group polymorphism occurs in $~ 30 \%$ of African Americans but is rare in Caucasians ${ }^{12}$. We tested a blinded panel of $\mathrm{Sl}\left(\mathrm{a}^{+}\right)$and $\mathrm{Sl}\left(\mathrm{a}^{-}\right) \mathrm{RBC}$ for their ability to bind to DBL-1 of $R 29 R^{+}$var1 expressed in COS-7 cells. RBC from each donor were characterized for their CR1 copy number and $\mathrm{Sl}(\mathrm{a})$ type (Table 2). $\mathrm{Sl}\left(\mathrm{a}^{-}\right) \mathrm{RBC}$ consistently showed lower binding to DBL-1 than $\operatorname{did~Sl}\left(\mathrm{a}^{+}\right)$controls $(P=0.0001)$. Confirmation that $\mathrm{Sl}\left(\mathrm{a}^{-}\right)$and another high-frequency polymorphism of CR1 in Africans $\left(\mathrm{McC}\left(\mathrm{b}^{+}\right)^{12}\right.$ are protective alleles will require molecular definition of the polymorphisms and their evaluation in large case-control studies of severe malaria.

Rosetting is a heterogeneous phenomenon in which a number of red-cell ligands (ABO blood group ${ }^{22}, \mathrm{CD} 36$ (ref. 18)) and soluble molecules (immunoglobulins $s^{26}$, sulphated glycoconjugates ${ }^{19}$ ) differentially modify the degree of rosette formation in different isolates. Small proteins (rosettins) on the infected RBC surface have also been associated with the rosetting phenotype ${ }^{6}$. Multiple pathways of rosette formation may exist, but the fact that rosetting of five independent parasites is reduced in $\mathrm{RBC}$ with low expression of CR1 suggests that CR1 may play a common but not exclusive role

Table 2 Binding of a blinded panel of $\mathrm{SI}\left(\mathrm{a}^{+}\right)$and $\mathrm{SI}\left(\mathrm{a}^{-}\right)$erythrocytes to COS-7 cells expressing DBL-1 of $R 29 R^{+}$var1

\begin{tabular}{|c|c|c|c|c|c|c|c|c|}
\hline \multirow[b]{2}{*}{ Donor } & \multirow[b]{2}{*}{ Race $^{*}$} & \multirow[b]{2}{*}{ CR1 copy number } & \multirow[b]{2}{*}{ SI(a) Type } & \multicolumn{5}{|c|}{ Binding $\dagger$ to COS-7 cells expressing DBL-1 } \\
\hline & & & & $\begin{array}{c}\text { Expt } \\
1\end{array}$ & $\begin{array}{c}\text { Expt } \\
2\end{array}$ & Expt 3 & Expt 4 & Expt 5 \\
\hline \multicolumn{9}{|l|}{ Set 1} \\
\hline 960673 & W & 180 & - & 7,8 & 21,15 & ND丰 & ND & ND \\
\hline 960675 & $\mathrm{~B}$ & 251 & - & 13,9 & 14,7 & ND & ND & ND \\
\hline 960676 & $\mathrm{~B}$ & 309 & - & 31,23 & 38,31 & ND & ND & ND \\
\hline 960671 & W & 229 & + & 38,29 & 56,32 & ND & ND & ND \\
\hline 960670 & $\mathrm{~B}$ & 205 & + & 61,55 & 72,81 & ND & ND & ND \\
\hline 960674 & W & 372 & + & 62,61 & 76,70 & ND & ND & ND \\
\hline \multicolumn{9}{|l|}{ Set 2} \\
\hline 960729 & B & 273 & - & ND & 19,14 & 21,36 & ND & ND \\
\hline 960014 & $\mathrm{~B}$ & 298 & + & ND & 47,38 & 49,66 & ND & ND \\
\hline 920560 & $\mathrm{~B}$ & 332 & + & ND & 70,47 & 85,87 & ND & ND \\
\hline 960048 & $\mathrm{~B}$ & 336 & + & ND & 71,87 & 76,123 & ND & ND \\
\hline \multicolumn{9}{|l|}{ Set 3} \\
\hline 960746 & $B$ & 274 & - & ND & ND & ND & $0,8,2$ & $11,19,8$ \\
\hline 960745 & B & 342 & - & ND & ND & ND & $9,14,7$ & $18,28,11$ \\
\hline 960748 & $\mathrm{H}$ & 325 & + & ND & ND & ND & $53,38,38$ & $53,88,68$ \\
\hline
\end{tabular}

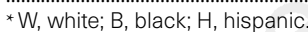

† Data shown are number of positive COS-7 cells in 50 fields at $200 \times$ magnification for two coverslips (experiments 1-3) or three coverslips (experiments 4 and 5 ). The binding data were

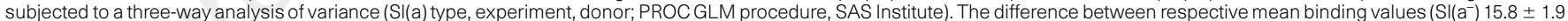
s.e. versus SI $\left(\mathrm{a}^{+}\right) 62,3 \pm 3.8$ s.e.) accounted for two-thirds of the overall observed variability and was significant at the 0.0001 level (18.3, 42 degrees of freedom). $\ddagger$ ND, not determined.

a

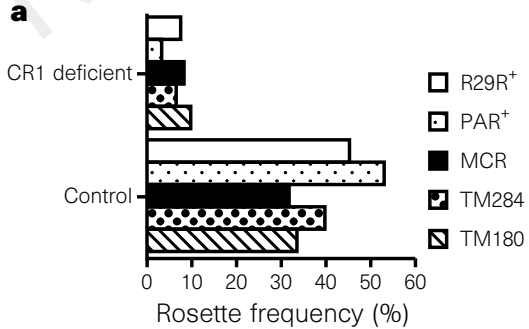

c

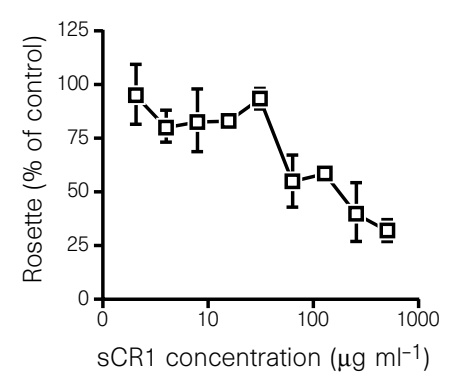

b

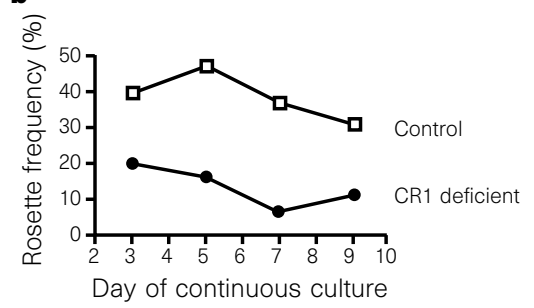

d

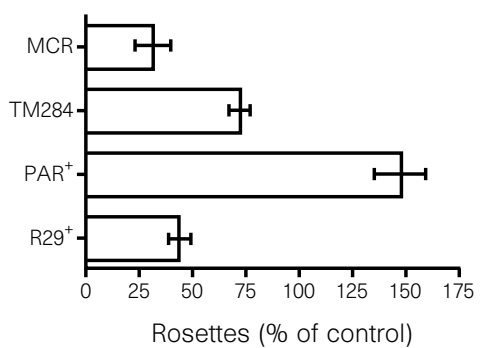

Figure $2 \mathrm{CR} 1$ is required for $P$. falciparum rosetting. a, Rosette formation of fresh CR1-deficient RBC (donor $\mathrm{MH} ; \mathrm{CR} 1$ copy number, 28) with five parasite clones/ lines. $\mathbf{b}$, Rosetting of R29 grown in continuous culture in CR1-deficient (donor BS; CR1 copy number, 60) and normal RBC. c, Dose-dependent inhibition of R29 rosetting by SCR1. Rosetting at each SCR1 concentration is expressed as a percentage of the rosette frequency in control R29 with no added SCR1. Data shown are mean and standard error of triplicate determinations of rosette frequency at each concentration from a representative experiment. Two additional experiments gave similar results. d, Effect of $100 \mathrm{\mu g} \mathrm{ml}^{-1}$ SCR1 on four parasite clones/lines. Rosetting is expressed as a percentage of the control rosette frequency for each clone/line without added SCR1. Data shown are mean and standard error from three $\left(\mathrm{R}^{2} 9 \mathrm{R}^{+}, \mathrm{PAR}^{+}\right.$and MCR) or four (TM284) independent experiments. 
in the process and may contribute to a more complex multimolecular interaction involving PfEMP-1. Although rosetting is associated with severe disease in most studies, the present data cannot distinguish between the possibilities that rosetting itself contributes to pathology by exacerbating microvascular obstruction or that it represents a surrogate marker for some other adhesive interaction with, for example, endothelial cells. Further insight into the molecular mechanisms involved may lead to new treatments and prevention of severe $P$. falciparum infections.

\section{Methods}

Parasite culture. Parasites were grown as described ${ }^{14}$. P. falciparum used were the clones R29 (ref. 14) and PAR ${ }^{+}$(ref. 6), and the lines MCR ${ }^{18}$, TM180 (ref. 22), and TM284 (ref. 22).

Gelatin sedimentation. Sedimentation of parasite culture in plasmagel ( $3 \%$ gelatin in isotonic saline) results in separation of rosetting and non-rosetting infected $\mathrm{RBC}^{13}$. The upper non-rosetting fraction is completely free of rosetting infected RBC, whereas the bottom fraction is predominantly rosetting infected RBC but always contains a small proportion of non-rosetting infected RBC. The weak band from RNA of the rosetting infected RBC with $\mathrm{R}^{-}$primers (Fig. 1c) reflects this contamination of the $\mathrm{R}^{+}$fraction.

RT-PCR. RNA extraction and RT-PCR of var gene DBL-1 were done as described $^{10}$ : upstream primer (primer 1), $1^{\prime}$ GC(T/C/A)TG(T/C)GCICCIT(T/A) $(\mathrm{C} / \mathrm{T})(\mathrm{C} / \mathrm{A}) \mathrm{G}$, which is specific for DBL-1; downstream primer, UNIEBP3', $5^{\prime}$ $\mathrm{CCA}(\mathrm{A} / \mathrm{T}) \mathrm{C}(\mathrm{T} / \mathrm{G})(\mathrm{T} / \mathrm{G}) \mathrm{A}(\mathrm{A} / \mathrm{G})(\mathrm{A} / \mathrm{G}) \mathrm{AATTG}(\mathrm{A} / \mathrm{T}) \mathrm{GG}$, which recognizes all DBL domains ${ }^{27}$. The $R 29 R^{+}$varl-specific primers were $5^{\prime}$-TGC ACC ATT CAG AAG ACA and $5^{\prime}$ TCC TTG ACT TGT AAA AGC. The $R 29 R^{-} v a r 3$-specific primers were $5^{\prime}$ CGA CGT CTA CAT CTA TGT and 5' ATT TTT CGC CTG TAG GTT. For the specific primers, 30 cycles of amplification were performed at $94^{\circ} \mathrm{C}$ for $30 \mathrm{~s}, 55^{\circ} \mathrm{C}$ for $30 \mathrm{~s}$ and $65^{\circ} \mathrm{C}$ for $1 \mathrm{~min} 30 \mathrm{~s}$.

COS-7 cell expression and RBC binding. Constructs for the expression of individual DBL domains as chimaeric proteins with the herpes simplex glycoprotein D signal sequence and transmembrane region were made using the pRE4 vector as described ${ }^{16}$. pR29R ${ }^{+}$dbll extends between nucleotides $244-$ 1,377 (numbered from the first ATG of $R 29 R^{+}$var 1), $\mathrm{pR}^{2} 9 \mathrm{R}^{+} \mathrm{cidr}$ from $1,276-$ $1,328, \mathrm{pR} 29 \mathrm{R}^{+} \mathrm{dbl} 2$ from $2,326-3,207, \mathrm{pR} 29 \mathrm{R}^{+} \mathrm{dbl} 3$ from 3,391-4,389, and pR29R ${ }^{+} \mathrm{dbl} 4$ from 4,774-6,117. COS-7 cells were grown on 12-mm coverslips in $35-\mathrm{mm}$ wells as described ${ }^{16}$ and transfected with $1 \mu \mathrm{g}$ DNA per well using Lipofectamine (Life Technologies). Surface expression was detected by immunofluorescence assay using the monoclonal antibody DL6 to the pRE4 vector ${ }^{17}$. Binding assays were carried out with RBC at 50\% haematocrit in binding medium (RPMI without bicarbonate, with $10 \%$ human serum) for $2 \mathrm{~h}$ at room temperature. Coverslips were washed gently with PBS0.1\% BSA to remove nonadherent RBC and viewed microscopically. A COS-7 cell was scored as positive when adherent RBC covered more than $50 \%$ of the cell surface. The number of positive cells in 50 fields at $200 \times$ magnification was counted.

Rosetting of RBC variants. Infected RBC were purified by heparin disruption of rosettes, followed by centrifugation through a Percoll gradient ${ }^{13}$ and were stained with $20 \mathrm{\mu g} \mathrm{ml}^{-1}$ ethidium bromide. The test RBC were thawed on the day of the experiment and labelled with the fluorescent dye PKH26 (ref. 28). Control experiments showed that freezing and thawing and labelling with PKH26 did not impair the ability of normal RBC to form rosettes. The test RBC were mixed with purified infected RBC and incubated at room temperature for $30 \mathrm{~min}$ on a plate shaker at 300 r.p.m. The rosette frequency (percentage of mature infected $\mathrm{RBC}$ in rosettes) was assessed by fluorescence microscopy. A minimum of 100 infected $\mathrm{RBC}$ were counted and scored for rosetting, a rosette being defined as the binding of two or more labelled RBC. The null/negative RBC tested were: Knops null (2 donors), Kell null (Ko), Bombay, Rh null, LW $\left(\mathrm{a}^{-} \mathrm{b}^{-}\right)$, McLeod, Kidd null (Jk-3), Duffy $\left(\mathrm{a}^{-} \mathrm{b}^{-}\right)$, Gerbich $(-1,-2,-3)$, Lutheran $\left(\mathrm{a}^{-} \mathrm{b}^{-}\right)$, Gregory $\left(\mathrm{a}^{-}\right)$, JMH null, $\mathrm{M}^{\mathrm{k}} \mathrm{M}^{\mathrm{k}}$, Scianna $(-1,-2), \mathrm{P}\left(\mathrm{Tja}^{-}\right)$, Colton $\left(a^{-} b^{-}\right)$, Adult $i$, Chido negative, Lewis $\left(a^{-} b^{-}\right)$, Xg negative, Diego $\left(b^{-}\right)$, Lan negative, and Vel negative.

Rosette inhibition with sCR1. sCR1 was a gift from D. Fearon ${ }^{23}$. Parasite cultures were stained with ethidium bromide and washed once and resuspended at $4 \%$ haematocrit in complete RPMI with $10 \%$ heat-inactivated human serum. An equal volume of sCR1 in RPMI was added and the rosettes disrupted by passing the suspension six times through a 25 -gauge needle. R29 was incubated with doubling dilutions of $\mathrm{SCR} 1$, giving a range of final concentrations from $500 \mu \mathrm{g} \mathrm{ml}^{-1}$ to $1.95 \mu \mathrm{g} \mathrm{ml}^{-1}$. $\mathrm{MCR}^{+}, \mathrm{PAR}^{+}$and TM284 were tested at $100 \mathrm{\mu g} \mathrm{ml}^{-1}$ of sCR1. Cultures were incubated at room temperature for $30 \mathrm{~min}$, then assessed by fluorescence microscopy, with 200 infected RBC counted and scored for rosetting.

Determination of CR1 copy number and SI(a) type. The mean CR1 copy number per RBC was determined by a double-antibody capture immunoassay using solubilized erythrocyte membranes ${ }^{21}$. $\mathrm{Sl}$ (a) type was determined by the antiglobulin technique ${ }^{29}$ using human antisera to $\mathrm{Sl}(\mathrm{a})$.

Received 17 March; accepted 12 May 1997.

1. Greenwood, B., Marsh, K. \& Snow, R. Why do some African children develop severe malaria? Parasitol Today 7, 277-281 (1991).

2. Carlson, J. et al. Human cerebral malaria: association with erythrocyte rosetting and lack of antirosetting antibodies. Lancet 336, 1457-1460 (1990).

3. Treutiger, C. J. et al. Rosette formation in Plasmodium falciparum isolates and anti-rosette activity of sera from Gambians with cerebral or uncomplicated malaria. Am. J. Trop. Med. Hyg. 46, 503-510 (1992).

4. Ringwald, P. et al. Parasite virulence factors during falciparum malaria rosetting, cytoadherence, and modulation of cytoadherence by cytokines. Infect. Immun. 61, 5198-5204 (1993).

5. Rowe, A., Obeiro, J., Newbold, C. I. \& Marsh, K. Plasmodium falciparum rosetting is associated with malaria severity in Kenya. Infect. Immun. 63, 2323-2326 (1995).

6. Helmby, H., Cavelier, L., Pettersson, U. \& Wahlgren, M. Rosetting Plasmodium falciparum-infected erythrocytes express unique strain-specific antigens on their surface. Infect. Immun. 61, 284-288 (1993).

7. Baruch, D. I., Gromley, J. A., Ma, C., Howard, R. J. \& Pasloske, B. L. Plasmodium falciparum erythrocyte membrane protein 1 is a parasitized erythrocyte receptor for adherence to CD36, thrombospondin, and intercellular adhesion molecule 1. Proc. Natl Acad. Sci. USA 93, 3497-3502 (1996)

8. Gardner, J. P., Pinches, R. A., Roberts, D. J. \& Newbold, C. I. Variant antigens and endothelial receptor adhesium in Plasmodium falciparum. Proc. Natl Acad. Sci. USA 93, 3503-3508 (1996).

9. Baruch, D. I. et al. Cloning the P. falciparum gene encoding PfEMP1, a malarial variant antigen and adherence receptor on the surface of parasitized human erythrocytes. Cell 82, 77-87 (1995).

10. Smith, J. D. et al. Switches in expression of Plasmodium falciparum var genes correlate with changes in antigenic and cytoadherent phenotypes of infected ethrocytes. Cell 82, 101-110 (1995).

11. Su, X.-Z. et al. A large and diverse family gene family (var) encodes $200-350 \mathrm{kD}$ proteins implicated in the antigenic variation and cytoadherence of Plasmodium falciparum-infected erythrocytes. Cell $\mathbf{8 2}$, 89-99 (1995).

12. Moulds, M. K. Serological investigation and clinical significance of high-titer, low-avidity (HTLA) antibodies. Am. Soc. Med. Technol. 47, 789-794 (1981).

13. Handunnetti, S. M. et al. Purification and in vivo selection of rosette-positive $\left(\mathrm{R}^{+}\right)$and rosettenegative $\left(\mathrm{R}^{-}\right)$phenotypes of knob-positive. Plasmodium falciparum parasites. Am. J. Trop. Med. Hyg. 46, 371-381 (1992)

14. Roberts, D. J. et al. Rapid switching to multiple antigenic and adhesive phenotypes in malaria. Nature 357, 689-692 (1992).

15. Arnold, C. \& Hodgson, I. J. Vectorette PCR: a novel approach to genome walking. PCR Meth. Appl. 1, 39-42 (1991).

16. Chitnis, C. E. \& Miller, L. H. Identification of the erythrocyte binding domains of Plasmodium vivax and Plasmodium knowlesi proteins involved in erythrocyte invasion. J. Exp. Med. 180, 497-506 (1994).

17. Cohen, G. H. et al. Expression of herpes simplex virus type 1 glycoprotein D deletion mutants in mammalian cells. J. Virus. 62, 1932-1940 (1988).

18. Handunnetti, S. M. et al. Involvement of CD36 on erythrocytes as a rosetting receptor for Plasmodium falciparum-infected erythrocytes. Blood 80, 2097-2104 (1992).

19. Rowe, A., Berendt, A. R., Marsh, K. \& Newbold, C. I. Plasmodium falciparum: a family of sulphated glycoconjugates disrupts erythrocytes rosettes. Exp. Parasitol. 79, 506-516 (1994).

20. Moulds, J. M., Moulds, J. J., Brown, M. \& Atkinson, J. P. Antiglobulin testing for CR1-related (Knops/ McCoy/Swain-Langley/York) blood group antigens: negative and weak reactions are caused by variable expression of CR1. Vox Sanguinis 62, 230-235 (1992).

21. Moulds, J. M., Nickells, M. W., Moulds, J. J., Brown, M. C. \& Atkinson, J. P. The C3b/C4b receptor is recognized by the Knops, McCoy, Swain-Langley and York blood group antisera. J. Exp. Med. 173, $1159-1163$ (1991).

22. Carlson, J. \& Wahlgren, M. Plasmodium falciparum erythrocyte rosetting is mediated by promiscuous lectin-like interactions. J. Exp. Med. 176, 1311-1317 (1992).

23. Weisman, H. F. et al. Soluble human complement receptor type 1: in vivo inhibitor of complement suppressing post-ischemic myocardial inflammation and necrosis. Science 249, 146-151 (1990).

24. Hill, A. V. S. Malaria resistance genes: a natural selection. Trans. R. Soc. Trop. Med. Hyg. 1992, 225-226 (1992).

25. Miller, L. H. Impact of malaria on genetic polymorphism and genetic diseases in Africans and African Americans. Proc. Natl Acad. Sci. USA 91, 2415-2419 (1994).

26. Scholander, C., Treutiger, C. J., Hultenby, K. \& Wahlgren, M. Novel fibrillar structure confers adhesive property to malaria-infected erythrocytes. Nature Med. 2, 204-208 (1996).

27. Peterson, D. S., Miller, L. H. \& Wellems, T. E. Isolation of multiple sequences from the Plasmodium falciparum genome that encode conserved domains homologous to those in erythrocyte-binding proteins. Proc. Natl Acad. Sci. USA 92, 7100-7104 (1995).

28. Yadava, A., Kumar, S., Dvorak, J. A., Milon, G. \& Miller, L. H. Trafficking of Plasmodium chabaudi adami-infected erythrocytes within the mouse spleen. Proc. Natl Acad. Sci. USA 93, 4595-4599 (1996).

29. Vengelen-Tyler, V. AABB Technical manual (American Association of Blood Banks, Bethesda, 1996).

Acknowledgements. We thank J. Proctor, D. Mallory, L. McCall and B. Smith for negative and null erythrocytes; M. Wahlgren and R. Howard for parasite clones/lines; G. Cohen and R. Eisenberg for the pRE4 plasmid and monoclonal antibodies; J. Smith for the A4var expression construct; D. Fearon for sCR1; D. Alling for statistical advice; and B. Sullivan for assistance in identifying $\mathrm{Sl}\left(\mathrm{a}^{-}\right)$donors. This work was funded by the Wellcome Trust (J.A.R. and C.I.N.), the National Blood Foundation (J.M.M.), and the was funded by the Wellcome Tr.
Arthritis Foundation (J.M.M.).

Correspondence and requests for materials to either J.A.R. (arowe@worf.molbiol.ox.ac.uk) or L.H.M. (louis miller@nih.gov). Sequences have been lodged with Genbank under accession numbers Y13402

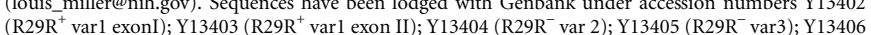

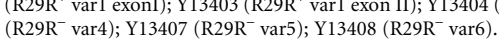

